\title{
Proactive palliative care for patients with COPD (PROLONG): a pragmatic cluster controlled trial
}

\author{
This article was published in the following Dove Press journal: \\ International Journal of COPD \\ 28 September 2017 \\ Number of times this article has been viewed
}

\section{RG Duenk' \\ CVerhagen' \\ EM Bronkhorst ${ }^{2}$ \\ PJWB van Mierlo 3,4 \\ MEAC Broeders ${ }^{5}$ \\ SM Collard ${ }^{6}$ \\ PNR Dekhuijzen ${ }^{7}$ \\ KCP Vissers' \\ Y Heijdra ${ }^{7, *}$ \\ $Y$ Engels ${ }^{1, *}$}

'Department of Anesthesiology, Pain and Palliative Medicine, ${ }^{2}$ Department of Health Evidence, Radboud

University Medical Center, Nijmegen,

${ }^{3}$ Department of Supportive and

Palliative Medicine, ${ }^{4}$ Department of

Geriatric Medicine, Rijnstate Hospital,

Arnhem, ${ }^{5}$ Department of Pulmonary

Diseases, Jeroen Bosch Hospital,

's-Hertogenbosch, ${ }^{6}$ Department of

Pulmonary Diseases, Meander Medical

Center, Amersfoort, ${ }^{7}$ Department

of Pulmonary Diseases, Radboud

University Medical Center, Nijmegen, the Netherlands

*These authors contributed equally to this work
Correspondence: RG Duenk

Department of Anesthesiology, Pain and Palliative Medicine, Radboud University Medical Center, PO Box 9101, 6500 HB Nijmegen, the Netherlands

$\mathrm{Tel}+3$ I 243666254

Fax +3I $2436 \mid 3585$

Email ria.duenk@radboudumc.nl
Background and aim: Patients with advanced chronic obstructive pulmonary disease (COPD) have poor quality of life. The aim of this study was to assess the effects of proactive palliative care on the well-being of these patients.

Trial registration: This trial is registered with the Netherlands Trial Register, NTR4037.

Patients and methods: A pragmatic cluster controlled trial (quasi-experimental design) was performed with hospitals as cluster (three intervention and three control) and a pretrial assessment was performed. Hospitals were selected for the intervention group based on the presence of a specialized palliative care team (SPCT). To control for confounders, a pretrial assessment was performed in which hospitals were compared on baseline characteristics. Patients with COPD with poor prognosis were recruited during hospitalization for acute exacerbation. All patients received usual care while patients in the intervention group received additional proactive palliative care in monthly meetings with an SPCT. Our primary outcome was change in quality of life score after 3 months, which was measured using the St George Respiratory Questionnaire (SGRQ). Secondary outcomes were, among others, quality of life at 6,9 and 12 months; readmissions: survival; and having made advance care planning (ACP) choices. All analyses were performed following the principle of intention to treat.

Results: During the year 2014, 228 patients (90 intervention and 138 control) were recruited and at 3 months, 163 patients (67 intervention and 96 control) completed the SGRQ. There was no significant difference in change scores of the SGRQ total at 3 months between groups $(-0.79$ [95\% CI, -4.61 to 3.34$], p=0.70)$. However, patients who received proactive palliative care experienced less impact of their COPD (SGRQ impact subscale) at 6 months ( $-6.22[-11.73$ to -0.71$], p=0.04$ ) and had more often made ACP choices (adjusted odds ratio 3.26 [1.49-7.14], $p=0.003$ ). Other secondary outcomes were not significantly different.

Conclusion: Proactive palliative care did not improve the overall quality of life of patients with COPD. However, patients more often made ACP choices which may lead to better quality of care toward the end of life.

Keywords: COPD, proactive palliative care, quality of life, advance care planning, readmission, survival

\section{Introduction}

Chronic obstructive pulmonary disease (COPD) is the third leading cause of death worldwide and caused 3.1 million deaths (5.6\% of total deaths) in 2012. ${ }^{1,2}$ This progressive life-threatening lung disease has an unpredictable course characterized by episodes of gradual decline punctuated by acute severe exacerbations. ${ }^{3}$ After the first hospitalization for an acute exacerbation of COPD (AECOPD), 50\% of patients die within 3.6 years. ${ }^{4}$ Patients with advanced COPD have a high symptom burden, 
including breathlessness, fatigue, cough, and anxiety. ${ }^{5}$ Their quality of life is poor and often even worse than patients with lung cancer. ${ }^{6}$

Early or proactive palliative care can improve the quality of life of patients with cancer ${ }^{7-9}$ and heart failure. ${ }^{10,11}$ This kind of care is not restricted to end-of-life care but can be delivered earlier in the disease course by anticipating on wishes and needs of patients, in order to prevent and relieve suffering from problems in the physical, psychosocial, and spiritual domain. ${ }^{2}$ Patients with lung cancer receiving proactive palliative care even had longer survival while receiving less aggressive treatments. ${ }^{8}$ Prolonged survival has also been observed in patients with refractory breathlessness (cancer, COPD, chronic heart failure [CHF], and interstitial lung disease). ${ }^{12}$ In this study of Higginson et al, ${ }^{12}$ early introduction of a palliative breathlessness support service improved breathlessness mastery, a quality of life domain of the Chronic Respiratory Disease Questionnaire. Although proactive palliative care has been shown to improve the quality of life and prolong survival of patients with various life-threatening diseases, it is still not common for patients with COPD to receive this care. ${ }^{13}$ Since little is known about the effects of proactive palliative care in COPD, research is needed to be able to improve care for this patient group. ${ }^{13}$

We report a pragmatic cluster controlled trial of proactive palliative care in patients with COPD. A cluster design was chosen to prevent contamination and to minimize ethical concerns of patients and clinicians with respect to randomization and gate keeping. We hypothesized that patients with COPD who received proactive palliative care integrated with usual care compared to patients who received usual care only would have better quality of life, lower levels of psychological distress, fewer and shorter hospital admissions for an AECOPD, and prolonged survival and that receiving proactive palliative care would increase the number of patients with whom advance care planning (ACP) choices were made.

\section{Patients and methods}

\section{Study design}

This trial is registered with the Netherlands Trial Register, NTR4037. A pragmatic cluster controlled trial (quasiexperimental design) was performed in general hospitals in the Netherlands with a general hospital as cluster (three control and three intervention). Patients were recruited between January 6, 2014 and January 8, 2015, and each patient was followed up for 1 year. Hospitals were selected for the intervention group based on the presence of a specialized palliative care team (SPCT). A pretrial assessment was performed to be able to control for confounders on hospital level. All outcome measures were on patient level.

\section{Participants}

Patients with COPD, 18 years or older, who had a hospital admission for an AECOPD were considered for the PROLONG study. ${ }^{14}$ Patients were excluded if they could not speak Dutch, had severe cognitive disorders, or if they were being treated by an SPCT at the moment of inclusion. The attending pulmonologist selected and approached potential participants. Exclusion because of severe cognitive disorder was based on judgment of the pulmonologist. If the patient agreed to participate, an informed consent was signed. For the intervention study described here, only patients with poor prognosis were regarded. To identify these patients, the pulmonologist completed a standard checklist consisting of a set of 11 indicators derived from the literature. ${ }^{14}$ If meeting two or more indicators, the patient was considered to have a poor prognosis and eligible to participate in the study. The set of indicators of poor prognosis is presented in Table $1 .{ }^{15,16}$

Table I Set of indicators of poor prognosis

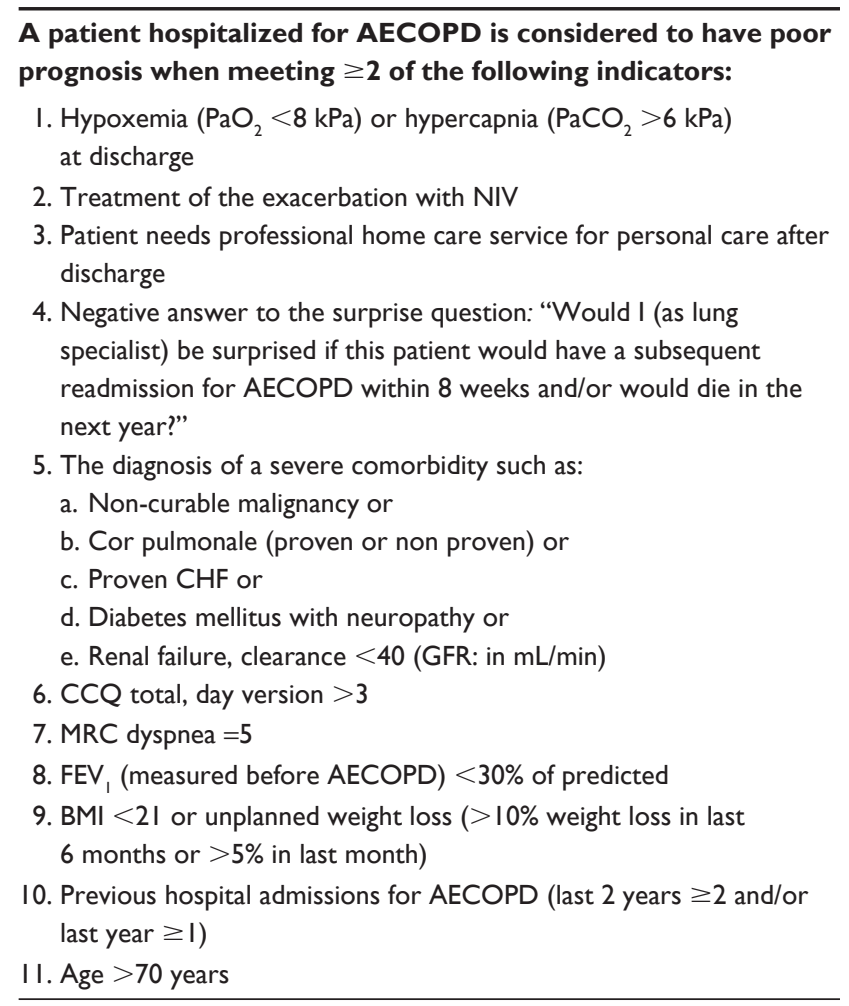

Abbreviations: AECOPD, acute exacerbation of chronic obstructive pulmonary disease; BMI, body mass index; CCQ, Clinical COPD Questionnaire; CHF, chronic heart failure; $F V_{1}$, forced expiratory volume in I second; GFR, glomerular filtration rate; MRC dyspnea, Medical Research Council dyspnea questionnaire; NIV, noninvasive ventilation. 
The study protocol was approved by the medical ethics committee (METC) of the Radboud University Medical Center, Nijmegen (METC protocol number 2012/260). Thereafter, research approval was received in all participating hospitals. Our protocol followed CONSORT recommendations,${ }^{14}$ but there were two protocol deviations. First, patients participating in other COPD-related studies were withdrawn from the intention-to-treat analysis from the moment they entered the other study. Second, patients who signed the informed consent but died in hospital during inclusion were also excluded as the pulmonologist was not able to complete the checklist because it consisted of indicators for posthospital mortality. A comprehensive description of the methods is given in the published protocol. ${ }^{14}$

\section{Randomization}

A cluster design was chosen to prevent contamination and to minimize ethical concerns of patients and clinicians with respect to randomization and gate keeping. Contamination would certainly have taken place because our intervention involved a close cooperation between pulmonary team and SPCT. At the time of hospital recruitment, a minority of hospitals in the Netherlands had the availability of an SPCT. Since only four hospitals with an SPCT were willing to participate, it was not possible to create comparable groups through randomization in our trial. Instead, we performed a pragmatic cluster controlled trial (quasiexperiment), in which three hospitals with an SPCT were selected for the intervention and three hospitals without an SPCT for the control group. To control for confounders on hospital level, a pretrial assessment was performed in which hospitals were compared on baseline characteristics over the year before trial (the number of hospitalizations and hospitalization days for AECOPD per patient, and percentage of patients hospitalized for an AECOPD who died in hospital). All outcome measures were on patient level, and patients performed a pre- and post-intervention measurement.

The study was single blinded. Clinicians were aware of treatment allocation, while patients were unaware of the existence of another group.

\section{Interventions}

All patients received usual care. In the intervention group, patients received additional proactive palliative care from an SPCT. Patients had a first consultation with the SPCT during the initial hospitalization, or the latest within 1 week after hospital discharge. Thereafter, the SPCT had monthly meetings with the patient in the outpatient setting, preferably face to face but alternatively by telephone, for 1 year or until death.

Since delivering proactive palliative care for patients with COPD was not common for members of the SPCTs, they received a training, aimed at the specific problems in this patient group, which was provided by academic palliative care professionals of the Radboud University Medical Center, Nijmegen. Training was based on the specific guidelines for palliative care in $\mathrm{COPD}^{17}$ and consisted of two 3-hour meetings. The first meeting took place in the month before trial, and the second during the first month of trial. The training consisted of the following topics: how to communicate future care planning and end-of-life aspects with the patients and their families; how to create a patient-tailored proactive palliative care plan; how to proactively anticipate on illness and death scenarios; how to organize transfer of care to the pulmonologist and general practitioner (GP); and how to perform a proactive palliative care plan in cooperation with the pulmonologist.

\section{Data collection}

Data collection took place using questionnaires completed by the patients and by retrospectively collecting data from their medical files over the trial period (Table 2). ${ }^{18-21}$

$\mathrm{ACP}$ choices documented in medical files were defined as agreements about: not to be resuscitated (NTBR) policy, intensive care unit (ICU) admission, palliative dyspnea treatment, palliative sedation, treatment of future infections with antibiotics $(\mathrm{AB})$, and preferred place of death. These ACP choices were our objective outcome measures which served as a proxy for measuring whether ACP conversations had taken place.

\section{Outcomes}

The primary outcome was change in the quality of life from baseline after 3 months measured with the St George Respiratory Questionnaire (SGRQ). Secondary questionnaire outcomes were change of the SGRQ from baseline after, respectively, 6, 9, and 12 months and change of the McGill Quality of Life Questionnaire (McGill) and the Hospital Anxiety and Depression Scale (HADS) from baseline after, respectively, 3, 6, 9, and 12 months. Secondary outcomes retrospectively retrieved from the medical files of the patients over the trial period are presented in Table 2.

\section{Statistical analysis}

Based on our primary outcome, change in quality of life measured with the SGRQ from baseline after 3 months, 
Table 2 Overview of data collection per time point

\begin{tabular}{|c|c|c|c|c|c|c|}
\hline Data collection & B & $3 \mathbf{m}$ & $6 \mathrm{~m}$ & $9 \mathrm{~m}$ & $12 \mathrm{~m}$ & $\mathbf{R}$ \\
\hline \multicolumn{7}{|l|}{ Questionnaires } \\
\hline $\begin{array}{l}\text { Demographic questionnaire (age, pack years, sex, marital status, place, and conditions } \\
\text { of living and education) }\end{array}$ & $x$ & & & & & \\
\hline SGRQ (COPD quality of life questionnaire; symptoms, activities, and impacts subscales) & $x$ & $x$ & $\mathrm{x}$ & $\mathrm{x}$ & $\mathrm{X}$ & \\
\hline $\begin{array}{l}\text { McGill (palliative quality of life questionnaire; phys symptoms, phys and psych well-being, } \\
\text { existential, and support subscales) }\end{array}$ & $\mathrm{x}$ & $\mathrm{X}$ & $\mathrm{X}$ & $\mathrm{X}$ & $\mathrm{X}$ & \\
\hline HADS (psych well-being questionnaire; anxiety and depression subscales) & $\mathrm{x}$ & $\mathrm{X}$ & $\mathrm{x}$ & $\mathrm{x}$ & $\mathrm{X}$ & \\
\hline \multicolumn{7}{|l|}{ Medical files (information over the I-year trial period) } \\
\hline Number of readmissions to hospital & & & & & & $x$ \\
\hline Number of readmissions to hospital for AECOPD & & & & & & $x$ \\
\hline Date of first readmission for AECOPD & & & & & & $x$ \\
\hline Number of days of readmission to hospital for AECOPD & & & & & & $\mathrm{x}$ \\
\hline Choices of ACP documented in the medical file at baseline & & & & & & $x$ \\
\hline Choices of ACP documented in the medical file after I year or at death & & & & & & $x$ \\
\hline Did the patient die within I year after inclusion? & & & & & & $\mathrm{x}$ \\
\hline Date of death & & & & & & $\mathrm{x}$ \\
\hline
\end{tabular}

Note: X's indicate the times that that type of data was collected.

Abbreviations: ACP, advance care planning; AECOPD, acute exacerbation of chronic obstructive pulmonary disease; B, baseline; HADS, Hospital Anxiety and Depression Scale; m, months; McGill, McGill Quality of Life Questionnaire; phys, physical; psych, psychological; R, retrospectively; SGRQ, St George Respiratory Questionnaire.

we estimated that 64 patients were needed in each arm to detect a mean difference of 9 (SD 16) with a $p$-value of 0.05 at a power of $80 \%{ }^{22}$ To adjust for clustering at hospital level (intraclass correlation coefficient [ICC] $=0.01$, three hospitals per arm) and to allow for an additional loss to follow up of $10 \%$, a total of 86 patients were required in each arm.

We used the valid CASTOR data management system to ensure good clinical practice. ${ }^{23}$ Data were analyzed using $\mathrm{R}$ software, version 3.1.2. Frequencies, means, and standard deviations (SDs) were used to describe the study variables. Linear mixed models with a random intercept for hospitals to account for clustering were used to study the effects of proactive palliative care on the primary and secondary outcomes. The models contained an adjustment for baseline scores of which selection was based on theoretical background and differences between groups at baseline. The analysis followed the principle of intention to treat. Missing data were handled using available case analysis.

Survival was plotted using the Kaplan-Meier method. We calculated survival rates until 365 days from enrollment in both groups. A Cox proportional hazard test was used to assess the effect of proactive palliative care on survival with adjustment for baseline characteristics. Again, mixed models with a random intercept for hospitals were used.

\section{Results}

In six general hospitals, 780 patients were screened, of whom 228 (90 intervention and 138 control) were included in the intention-to-treat analysis (Figure 1).
Baseline characteristics at hospital level over the year before trial (2013) are presented in Table 3.

Tables 4 and 5 summarize the demographics and baseline characteristics of the study population, respectively. In the intervention group, compared to the control group, more patients had severe dyspnea scores, were living alone, and were suffering from CHF. No substantial differences were seen between groups on baseline outcome measures.

Important change scores relative to baseline and the associated tests of effects between groups are presented in Table $6 .{ }^{24}$ The outcomes of the McGill and HADS subscales are presented in Table S1. In the linear mixed models, the baseline scores on patient level adjusted for were: baseline questionnaire score, sex, condition of living, level of education, pack years, Medical Research Council (MRC) dyspnea score, forced expiratory volume in 1 second $\left(\mathrm{FEV}_{1} \%\right)$ of predicted value, presence of comorbidity, number of indicators met, and number of admissions for AECOPD in the previous 2 years. To account for differences at baseline on hospital level, we also adjusted for number of hospitalizations for AECOPD per patient in the year before the trial (2013).

Incorrectly filled out questions were noticed at the McGill physical symptoms subscale. In an open text field, patients had to describe a troublesome physical symptom and indicate its seriousness on a visual analog scale (VAS). This question proved to be subject to misinterpretation. Patients often listed not a physical symptom but a disease (eg, diabetes), or a complaint of other origin (eg, snoring partner). To prevent from too many missing values, we calculated the McGill 


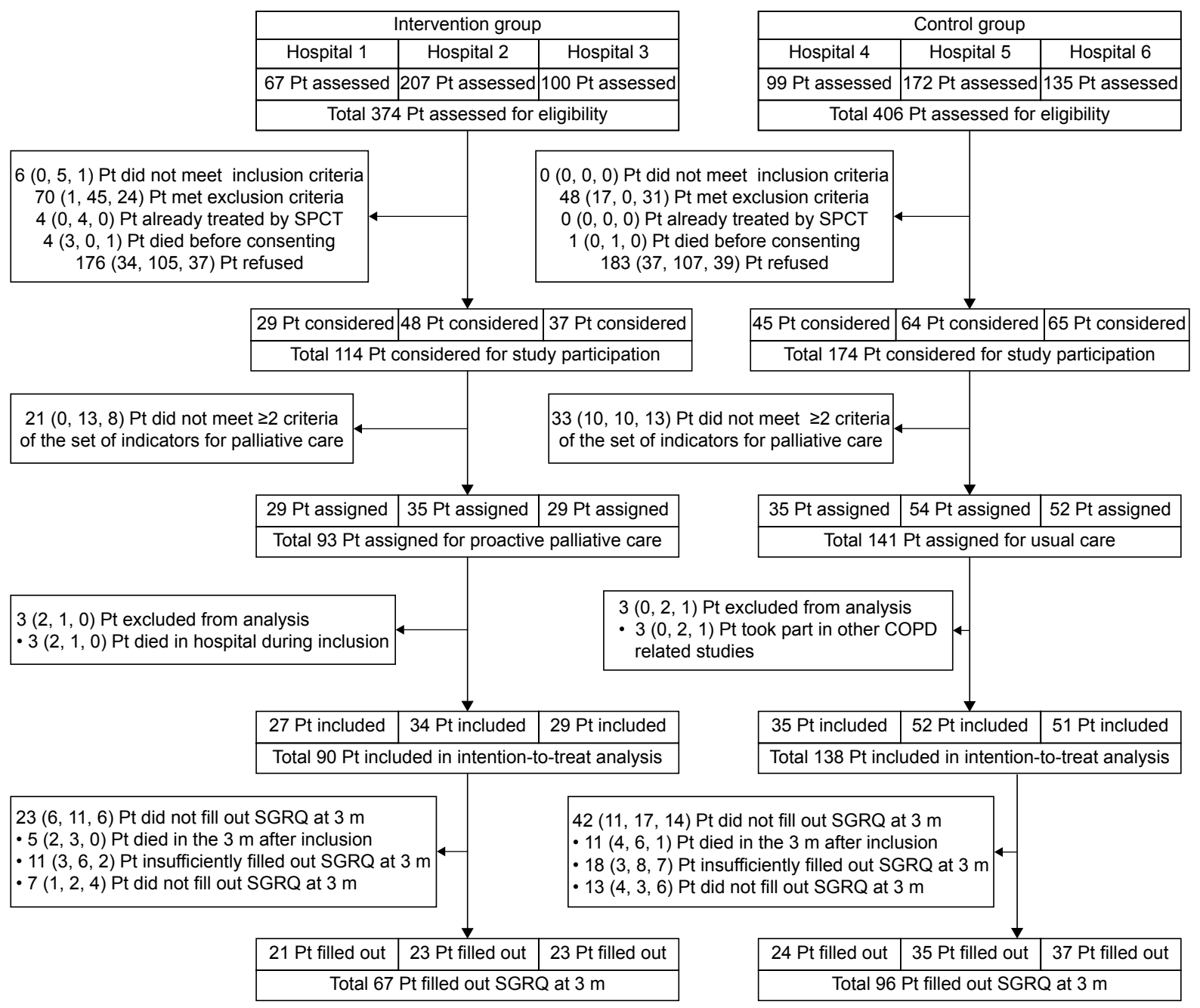

Figure I Trial profile.

Notes: Data presented as $\mathrm{N}$ ( $\mathrm{n}$ for $\mathrm{HI}, \mathrm{n}$ for H2, $\mathrm{n}$ for H3) unless otherwise indicated for Intervention group. Data presented as $\mathrm{N}$ ( $\mathrm{n}$ for $\mathrm{H} 4, \mathrm{n}$ for H5, $\mathrm{n}$ for H6) unless otherwise indicated for Control group.

Abbreviations: m, months; Pt, patients; SGRQ, St George Respiratory Questionnaire; SPCT, specialized palliative care team; HI, hospital I; H2, hospital 2; H3, hospital 3; $\mathrm{H} 4$, hospital 4; H5, hospital 5; H6, hospital 6.

total score by taking the mean of the remaining four of the five subscales.

The primary outcome of change scores in SGRQ total at 3 months did not differ significantly between groups (mean [SD] observed change score in intervention group -1.84 [12.20] vs control group 0.20 [12.05], $p=0.70$ ).

There was a significant difference between groups in the change scores of the impact subscale of the SGRQ at 6 months $(-5.73$ [16.21] vs 0.86 [18.73], $p=0.04)$. We also noted a significant difference between groups in number of patients who made ACP choices during the year of trial (76.7\% vs $59.4 \%$, adjusted odds ratio [OR] 3.26 [95\% CI $1.49-7.14], p=0.003)$. Of the $36.8 \%$ of patients $(30.0 \%$ intervention and $41.3 \%$ control) who had not made ACP choices at baseline, $85.7 \%$ (100\% intervention and $78.9 \%$ control) made ACP choices within the next year. Whereas, of the $63.2 \%$ of patients $(70.0 \%$ intervention and $58.7 \%$ control) who had already made ACP choices at baseline, $54.9 \%$

Table 3 Baseline characteristics at hospital level over the year before trial (2013)

\begin{tabular}{|c|c|c|c|c|c|c|c|c|}
\hline \multirow[t]{2}{*}{ Characteristics } & \multicolumn{4}{|c|}{ Intervention } & \multicolumn{4}{|l|}{ Control } \\
\hline & Hospital I & Hospital 2 & Hospital 3 & Mean & Hospital 4 & Hospital 5 & Hospital 6 & Mean \\
\hline Hospitalizations for AECOPD per patient (n) & 1.32 & 1.60 & 1.24 & 1.39 & 1.23 & 1.51 & 1.21 & 1.32 \\
\hline Hospitalization days for AECOPD per patient $(n)$ & 9.21 & 10.58 & 10.15 & 9.98 & 9.30 & 12.32 & 10.43 & 10.68 \\
\hline Patients with AECOPD who died in hospital (\%) & 0.08 & 0.07 & 0.07 & 0.073 & 0.06 & 0.12 & 0.06 & 0.08 \\
\hline
\end{tabular}

Abbreviation: AECOPD, acute exacerbation of chronic obstructive pulmonary disease. 
Table 4 Demographics of the intention-to-treat population

\begin{tabular}{|c|c|c|c|}
\hline Demographics & $\begin{array}{l}\text { Overall } \\
(n=228)\end{array}$ & $\begin{array}{l}\text { Intervention } \\
(\mathrm{n}=90)\end{array}$ & $\begin{array}{l}\text { Control } \\
(n=138)\end{array}$ \\
\hline Age (years) & $68.54(9.34)$ & $68.67(9.08)$ & $68.45(9.54)$ \\
\hline Pack years & $40.00(31.76)$ & $41.58(28.95)$ & $38.92(33.62)$ \\
\hline \multicolumn{4}{|l|}{ Sex } \\
\hline Male & II 0 (48.2\%) & $46(51.1 \%)$ & $64(46.4 \%)$ \\
\hline \multicolumn{4}{|l|}{ Marital status ${ }^{\mathrm{a}}$} \\
\hline Unmarried & $16(7.0 \%)$ & $5(5.6 \%)$ & II (8.0\%) \\
\hline Married & $145(63.6 \%)$ & $5 \mathrm{I}(56.7 \%)$ & $94(68.1 \%)$ \\
\hline Divorced & $25(11.0 \%)$ & $12(13.3 \%)$ & $13(9.4 \%)$ \\
\hline Widowed & 39 (17.1\%) & $22(24.4 \%)$ & $17(12.3 \%)$ \\
\hline \multicolumn{4}{|l|}{ Living situation ${ }^{\mathrm{a}}$} \\
\hline Single & $7 \mathrm{l}(3 \mathrm{I} .1 \%)$ & $36(40.0 \%)$ & $35(25.4 \%)$ \\
\hline Not single & $145(63.6 \%)$ & $49(54.4 \%)$ & $96(69.6 \%)$ \\
\hline \multicolumn{4}{|l|}{ Place of residence ${ }^{a}$} \\
\hline Home, independent of home care & 144 (63.2\%) & $60(66.7 \%)$ & $84(60.9 \%)$ \\
\hline Home, dependent of home care & $74(32.5 \%)$ & $27(30.0 \%)$ & 47 (34.1\%) \\
\hline Residential home & $3(1.3 \%)$ & I (I.I\%) & $2(1.4 \%)$ \\
\hline Nursing home & $\mathrm{I}(0.4 \%)$ & I (I.I\%) & $0(0 \%)$ \\
\hline \multicolumn{4}{|l|}{ Highest level of education ${ }^{\mathrm{a}}$} \\
\hline No education & $2(0.9 \%)$ & I (I.1\%) & I (0.7\%) \\
\hline Elementary school & $38(16.7 \%)$ & $16(17.8 \%)$ & $22(\mid 5.9 \%)$ \\
\hline Secondary school & $57(25.0 \%)$ & $18(20.0 \%)$ & $39(28.3 \%)$ \\
\hline Primary education & 45 (19.7\%) & 17 (I8.9\%) & $28(20.3 \%)$ \\
\hline Secondary education & $57(25.0 \%)$ & $30(33.3 \%)$ & $27(19.6 \%)$ \\
\hline Higher/university education & $23(10.1 \%)$ & $8(8.9 \%)$ & $15(10.9 \%)$ \\
\hline
\end{tabular}

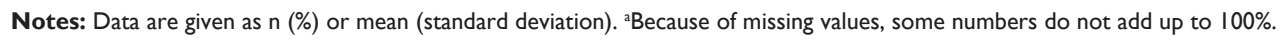

(66.7\% intervention and $45.7 \%$ control) made additional ACP choices within the next year. All other secondary outcome measures were not significantly different between groups. One year after enrollment, 52 patients with poor prognosis $(22.8 \%)$ had died. The Kaplan-Meier curve is shown in Figure 2. The Cox proportional hazard test showed that survival was not significantly different between groups (adjusted hazard ratio [HR] 0.74 [95\% CI 0.34-1.62], $p=0.45$ ).

\section{Discussion}

This is the first study to explore the effects of proactive palliative care in a large group of patients with COPD with poor prognosis $(n=228)$. We did not find an effect on our primary outcome: the change in quality of life measured using the SGRQ from baseline to 3 months was not different between groups. However, patients receiving proactive palliative care experienced less impact of their COPD (SGRQ impact subscale) at 6 months than patients receiving usual care. The change in symptoms and activity level (SGRQ symptoms and activity subscale) was not different between groups at 3, 6, 9 , and 12 months. Moreover, there was a relevant difference in the number of patients who made ACP choices during the year of trial, in favor of the intervention group. We did not find a difference in other questionnaire outcomes, nor in number and length of hospital admissions or in survival between groups.

There are several possible reasons at the level of identification, organization, patient, outcome measure, and disease course that may explain the failure to show an improvement of quality of life in patients with COPD by means of proactive palliative care in our study. First, $22.8 \%$ of patients identified as having a poor prognosis died; it is possible that our criteria for poor prognosis were too broad. Second, patients with advanced COPD are often homebound until they enter an acute phase with hospitalization. ${ }^{25}$ Continuity of palliative care can therefore only be achieved with a coordinated, multidisciplinary care approach. ${ }^{26}$ This requires collaboration between primary and secondary health care professionals. Although GPs were informed about the intervention and the SPCT was encouraged to collaborate with GPs, it is unknown to what extent this occurred. Third, patients with COPD generally have a lower social economic status (SES), ie, on average a lower level of education and less financial means compared to other patient groups. ${ }^{27}$ These aspects have an impact on COPD health outcomes. ${ }^{27}$ Indeed, some patients in our study had difficulties understanding certain questions, which resulted in the return of incomplete questionnaires. Besides, some patients lacked financial means to afford 
Table 5 Baseline characteristics of the intention-to-treat population

\begin{tabular}{|c|c|c|c|}
\hline Characteristics & $\begin{array}{l}\text { Overall } \\
(n=228)\end{array}$ & $\begin{array}{l}\text { Intervention } \\
(\mathrm{n}=90)\end{array}$ & $\begin{array}{l}\text { Control } \\
(n=138)\end{array}$ \\
\hline \multicolumn{4}{|l|}{ Clinical characteristics } \\
\hline $\mathrm{FEV}_{1}(\mathrm{~L})$ & $1.07(0.49)$ & $1.05(0.47)$ & $1.08(0.50)$ \\
\hline Predicted FEV $(\%)$ & $42.5 I(18.87)$ & $40.79(16.09)$ & $43.70(20.55)$ \\
\hline $\mathrm{VC}(\mathrm{L})$ & $2.60(0.82)$ & $2.63(0.83)$ & $2.58(0.82)$ \\
\hline Predicted VC (\%) & $79.84(20.67)$ & $79.75(21.90)$ & $79.90(19.89)$ \\
\hline \multicolumn{4}{|l|}{ GOLD stage $e^{a, b}$} \\
\hline 0 & 10 (4.4\%) & $4(4.4 \%)$ & $6(4.3 \%)$ \\
\hline I & $7(3.1 \%)$ & $2(2.2 \%)$ & $5(3.6 \%)$ \\
\hline ॥ & $5 \mathrm{I}(22.4 \%)$ & $16(17.8 \%)$ & $35(25.4 \%)$ \\
\hline III & 87 (38.2\%) & $43(47.8 \%)$ & 44 (31.9\%) \\
\hline IV & $63(27.6 \%)$ & $24(26.7 \%)$ & $39(28.3 \%)$ \\
\hline \multicolumn{4}{|l|}{ Comorbidity } \\
\hline Non-curable malignancy & $12(5.3 \%)$ & $8(8.9 \%)$ & $4(2.9 \%)$ \\
\hline Cor pulmonale & $12(5.3 \%)$ & $3(3.3 \%)$ & $9(6.5 \%)$ \\
\hline $\mathrm{CHF}$ & $16(7.0 \%)$ & $\mathrm{II}(\mathrm{I} 2.2 \%)$ & $5(3.6 \%)$ \\
\hline DM with neuropathy & $9(3.9 \%)$ & $2(2.2 \%)$ & $7(5.1 \%)$ \\
\hline Renal failure & $13(5.7 \%)$ & $2(2.2 \%)$ & II (8.0\%) \\
\hline Comorbidity total & $58(25.4 \%)$ & $24(26.7 \%)$ & $34(24.6 \%)$ \\
\hline Hospitalizations. for AECOPD in previous 2 years $(n)$ & $1.95(2.57)$ & $2.28(3.1)$ & $1.73(2.14)$ \\
\hline Indicators met (n) & $4.35(1.64)$ & $4.42(1.5 \mathrm{I})$ & $4.30(1.72)$ \\
\hline \multicolumn{4}{|l|}{ MRC dyspnea } \\
\hline 0 & $4(1.8 \%)$ & $3(3.3 \%)$ & $\mathrm{I}(0.7 \%)$ \\
\hline I & $6(2.6 \%)$ & $3(3.3 \%)$ & $3(2.2 \%)$ \\
\hline 2 & $6(2.6 \%)$ & $\mathrm{I}(\mathrm{I} .1 \%)$ & $5(3.6 \%)$ \\
\hline 3 & $31(13.6 \%)$ & $5(5.6 \%)$ & $26(18.8 \%)$ \\
\hline 4 & $44(19.3 \%)$ & $15(16.7 \%)$ & $29(21.0 \%)$ \\
\hline 5 & $134(58.8 \%)$ & $63(70.0 \%)$ & 71 (5I.5\%) \\
\hline CCQ total & $3.45(0.97)$ & $3.48(0.88)$ & $3.44(1.03)$ \\
\hline \multicolumn{4}{|l|}{ Outcome measures } \\
\hline SGRQ total score & $68.12(14.43)$ & $69.00(13.37)$ & $67.50(15.15)$ \\
\hline SGRQ symptoms score & 69.80 (17.39) & $70.93(15.06)$ & $69.06(18.78)$ \\
\hline SGRQ activity score & $86.84(13.65)$ & $87.38(13.61)$ & $86.47(13.72)$ \\
\hline SGRQ impacts score & $57.57(19.56)$ & $58.16(18.77)$ & $57.16(20.13)$ \\
\hline McGill total score & $5.16(1.18)$ & $5.06(0.98)$ & $5.25(\mathrm{I} .3 \mathrm{I})$ \\
\hline McGill physical well-being & $4.03(2.26)$ & $4.28(2.28)$ & $3.87(2.23)$ \\
\hline McGill physical symptoms & $3.08(1.84)$ & $2.91(1.77)$ & $3.21(1.89)$ \\
\hline McGill psychological & $5.82(2.6 I)$ & $5.92(2.60)$ & $5.76(2.63)$ \\
\hline McGill existential & $5.55(1.67)$ & $5.6 \mathrm{I}(1.47)$ & $5.51(1.80)$ \\
\hline McGill support & 7.39 (1.91) & $7.61(1.63)$ & $7.24(2.07)$ \\
\hline HADS total score & I $6.87(7.80)$ & $16.48(7.88)$ & $17.13(7.78)$ \\
\hline HADS anxiety & $8.78(4.48)$ & $8.75(4.53)$ & $8.80(4.47)$ \\
\hline HADS depression & $8.12(4.29)$ & $7.74(4.12)$ & $8.37(4.40)$ \\
\hline
\end{tabular}

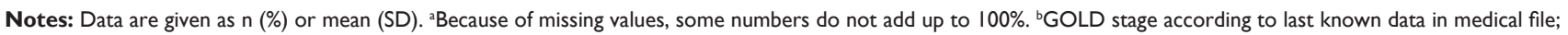
inclusion in the study based on judgment pulmonologist.

Abbreviations: AECOPD, acute exacerbation of chronic obstructive pulmonary disease; CCQ, Clinical COPD Questionnaire; CHF, congestive heart failure; DM, diabetes mellitus; $\mathrm{FEV}_{1}$, forced expiratory volume in I second; GOLD, Global Initiative on Obstructive Lung Disease; HADS, Hospital Anxiety and Depression Scale; McGill, McGill Quality of Life Questionnaire; MRC dyspnea, Medical Research Council dyspnea questionnaire; SD, standard deviation; SGRQ, St George Respiratory Questionnaire; VC, vital capacity.

transportation to the hospital, physical therapy, or even a walker. Fourth, for some patients with advanced COPD, filling in questionnaires may have been too demanding. Although all enrolled patients did consent to fill out questionnaires, about one out of five patients did not fully complete or return them. Incomplete data collection in advanced COPD has also been reported before. ${ }^{28,29}$ Perhaps in this population, the use of a qualitative instead of a quantitative approach is preferable for measuring changes in patient-reported outcomes. ${ }^{28}$ Finally, there are differences in the palliative trajectory between patients with cancer and those with COPD. The palliative trajectory of COPD is less predictable since 
Table 6 Change scores relative to baseline of the primary outcome (SGRQ total at 3 months) and secondary outcomes and associated tests of effects between groups

\begin{tabular}{|c|c|c|c|c|c|c|c|}
\hline \multirow[t]{3}{*}{ Outcomes } & \multicolumn{4}{|c|}{ Descriptives } & \multirow{2}{*}{\multicolumn{3}{|c|}{$\begin{array}{l}\text { Analysis of difference between groups for } \\
\text { changes over time }^{a}\end{array}$}} \\
\hline & \multicolumn{2}{|c|}{ Intervention } & \multicolumn{2}{|c|}{ Control } & & & \\
\hline & $\mathbf{n}$ & $\begin{array}{l}\text { Mean (SD) } \\
\text { observed change } \\
\text { from baseline }\end{array}$ & $\mathbf{n}$ & $\begin{array}{l}\text { Mean (SD) } \\
\text { observed change } \\
\text { from baseline }\end{array}$ & $\begin{array}{l}\text { Estimated difference } \\
(95 \% \mathrm{CI})\end{array}$ & $\begin{array}{l}\text { Effect } \\
\text { size }^{\text {b }}\end{array}$ & $p$-value \\
\hline \multicolumn{8}{|l|}{ SGRQ total ${ }^{\mathrm{c}}$} \\
\hline 3 months & 62 & $-1.84(12.20)$ & 88 & $0.20(\mid 2.05)$ & $-0.79(-4.61$ to 3.34$)$ & 0.17 & 0.70 \\
\hline 6 months & 55 & $-4.66(12.09)$ & 70 & $-1.64(13.11)$ & -2.20 (-6.63 to 2.22$)$ & 0.24 & 0.36 \\
\hline 9 months & 53 & $-3.94(11.34)$ & 69 & $0.29(11.90)$ & $-4.26(-8.55$ to 0.03$)$ & 0.36 & 0.07 \\
\hline 12 months & 45 & $-2.88(13.14)$ & 63 & $-0.50(12.48)$ & $-1.70(-6.71$ to 3.32$)$ & 0.19 & 0.54 \\
\hline \multicolumn{8}{|l|}{ SGRQ symptoms ${ }^{c}$} \\
\hline 3 months & 72 & $-4.34(15.79)$ & 109 & $-6.78(20.92)$ & $3.62(-1.71$ to 9.01$)$ & -0.13 & 0.21 \\
\hline 6 months & 65 & $-6.17(17.41)$ & 86 & $-4.40(19.77)$ & $-0.54(-6.27$ to 5.20$)$ & 0.09 & 0.86 \\
\hline 9 months & 59 & $-6.08(19.88)$ & 85 & $-6.37(20.70)$ & $-0.47(-6.78$ to 5.85$)$ & -0.01 & 0.89 \\
\hline 12 months & 53 & $-5.55(18.34)$ & 77 & $-6.88(20.90)$ & $3.77(-4.72$ to 12.25$)$ & -0.07 & 0.49 \\
\hline \multicolumn{8}{|l|}{ SGRQ activity } \\
\hline 3 months & 63 & $-1.74(14.88)$ & 91 & $-0.37(10.92)$ & $0.3 \mathrm{I}(-3.40$ to $4.0 \mathrm{I})$ & 0.11 & 0.87 \\
\hline 6 months & 57 & $-2.60(12.67)$ & 77 & $-1.78(12.22)$ & $0.83(-2.96$ to $4.6 \mathrm{I})$ & 0.07 & 0.69 \\
\hline 9 months & 57 & $-2.03(11.92)$ & 77 & $0.17(11.25)$ & $-0.70(-4.34$ to 2.95$)$ & 0.19 & 0.72 \\
\hline 12 months & 47 & $-2.45(12.45)$ & 70 & $-0.44(11.86)$ & $-2.06(-6.10$ to 1.98$)$ & 0.17 & 0.35 \\
\hline \multicolumn{8}{|l|}{ SGRQ impact ${ }^{c}$} \\
\hline 3 months & 73 & $-2.10(15.94)$ & 107 & $0.10(19.42)$ & $-2.69(-7.62$ to 2.24$)$ & 0.12 & 0.31 \\
\hline 6 months & 63 & $-5.73(16.21)$ & 85 & $0.86(\mid 8.73)$ & $-6.22(-11.73$ to -0.71$)$ & 0.37 & 0.04 \\
\hline 9 months & 59 & $-4.36(14.58)$ & 81 & $1.24(16.53)$ & $-5.30(-10.7 \mid$ to 0.11$)$ & 0.36 & 0.07 \\
\hline 12 months & 51 & $-1.27(18.24)$ & 78 & $0.25(20.74)$ & $-2.78(-9.49$ to 3.93$)$ & 0.08 & 0.45 \\
\hline \multicolumn{8}{|l|}{ McGill total ${ }^{\mathrm{d}, \mathrm{e}}$} \\
\hline 3 months & 60 & $0.08(1.62)$ & 79 & $0.13(1.73)$ & $0.26(-0.30$ to 0.83$)$ & 0.03 & 0.43 \\
\hline 6 months & 51 & $-0.04(1.50)$ & 70 & $-0.10(1.59)$ & $0.22(-0.24$ to 0.69$)$ & -0.04 & 0.38 \\
\hline 9 months & 44 & 0.05 (I.49) & 62 & $-0.22(1.56)$ & $0.14(-0.45$ to 0.73$)$ & -0.18 & 0.71 \\
\hline 12 months & 44 & $-0.17(1.55)$ & 56 & $-0.23(1.65)$ & $0.30(-0.40$ to 1.00$)$ & -0.04 & 0.44 \\
\hline \multicolumn{8}{|l|}{ HADS total ${ }^{c}$} \\
\hline 3 months & 76 & $0.22(6.8 I)$ & 112 & $0.27(6.30)$ & $-0.29(-2.19$ to 1.61$)$ & 0.01 & 0.78 \\
\hline 6 months & 66 & $0.46(7.20)$ & 90 & $0.39(6.43)$ & $-0.28(-2.39$ to 1.83$)$ & -0.01 & $0.8 \mathrm{I}$ \\
\hline 9 months & 62 & $-0.01(7.20)$ & 87 & $0.33(6.50)$ & $-0.49(-2.92$ to 1.94$)$ & 0.05 & 0.71 \\
\hline 12 months & 55 & $0.85(6.99)$ & 81 & $1.50(6.62)$ & $-1.01(-3.52$ to $1.5 \mathrm{I})$ & 0.10 & 0.46 \\
\hline Readmissions for AECOPD (n) & 90 & $1.72(1.76)$ & 135 & $1.65(2.00)$ & $-0.08(-0.39 \text { to } 0.23)^{f}$ & 0.04 & 0.62 \\
\hline \multirow[t]{2}{*}{ Days of readmission for AECOPD (n) } & 62 & $20.27(18.12)$ & 91 & $17.57(\mid 4.27)$ & $0.07(-0.25 \text { to } 0.39)^{g}$ & 0.17 & 0.57 \\
\hline & $\mathbf{n}$ & n (\%) & $\mathbf{n}$ & n (\%) & Adjusted OR $(95 \% \mathrm{CI})$ & & $p$-value \\
\hline \multirow[t]{2}{*}{ Patients who made ACP choices } & 90 & $69 / 90(76.7 \%)$ & 138 & $82 / 138(59.4 \%)$ & $3.26(1.49$ to 7.14$)$ & NA & 0.003 \\
\hline & $\mathbf{n}$ & n (\%) & $\mathbf{n}$ & n (\%) & Adjusted HR (95\% Cl) & & $p$-value \\
\hline Patients who died & 90 & $20 / 90(22.2 \%)$ & 138 & $32 / 138(23.7 \%)$ & $0.74(0.34-1.62)$ & NA & 0.45 \\
\hline $\begin{array}{l}\text { Notes: Associated tests of effects between } \\
\text { of intention to treat. Missing data were hanc } \\
\text { not displayed. "Associated tests of effects be } \\
0.50 \text { is moderate, and } 0.80 \text { is large. } .^{24} \text { 'Chan } \\
\text { "Change score interpretation: high score be } \\
\text { readmission for AECOPD" was used. }\end{array}$ & $\begin{array}{l}\text { oups } \\
\text { d usin } \\
\text { een g } \\
\text { score } \\
\text { r. } \mathrm{Ne}\end{array}$ & $\begin{array}{l}\text { ere estimated by linear mi } \\
\text { available case analysis. Th } \\
\text { pups were estimated by li } \\
\text { interpretation: low score } \\
\text { ative binomial regression }\end{array}$ & $\begin{array}{l}\text { ed mo } \\
\text { ICCs } \\
\text { ear mi } \\
\text { better. } \\
\text { nalysis. }\end{array}$ & $\begin{array}{l}\text { Is, adjusted for baseline cc } \\
\text { the questionnaire outcon } \\
d \text { models, adjusted for ba } \\
\text { McGill total score was } c r \\
\text { Because of skewness of } d\end{array}$ & $\begin{array}{l}\text { ariates. Analyses were perform } \\
\text { measures were all very small } \\
\text { eline covariates. }{ }^{\circ} \text { Effect sizes are } \\
\text { culated without the McGill phy } \\
\text { tribution, a logarithm of the va }\end{array}$ & $\begin{array}{l}\text { following } \\
\text { ar } 0 \text { or } 0 \text { a } \\
\text { Cohen's d, } \\
\text { cal sympto } \\
\text { ble "numb }\end{array}$ & $\begin{array}{l}\text { d therefore } \\
20 \text { is small, } \\
\text { is subscale. } \\
\text { of days of }\end{array}$ \\
\hline Abbreviations: $A C P$, advance care planning & & cute exacerbation of & & nfidence interval; HA & sspital Anxiety and Depres & & ard ratio; \\
\hline
\end{tabular}

episodes of gradual decline are punctuated by acute severe exacerbations; ${ }^{3}$ therefore, these acute exacerbations may have influenced findings defined at fixed time points.

Patients who received proactive palliative care experienced less impact of their COPD at 6 months. Although this may have been a chance finding, as it was a secondary outcome, merely an effect on the SGRQ impact subscale was also observed in the Glasgow supported self-management trial for patients with moderate-to-severe COPD. ${ }^{29}$ In addition, Higginson et $\mathrm{al}^{12}$ found no effect on quality of life from 


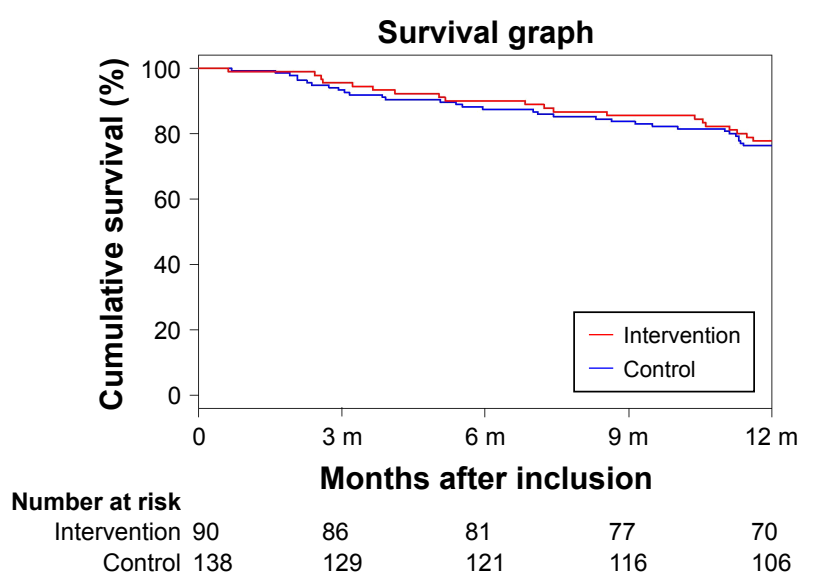

Figure 2 Kaplan-Meier plot of survival according to the study group.

Note: The Cox proportional hazard test showed that survival was not significantly different between the intervention and control group, adjusted $\mathrm{HR} 0.74(95 \% \mathrm{Cl}$ $0.34-1.62), p=0.45$.

Abbreviations: $\mathrm{Cl}$, confidence interval; $\mathrm{HR}$, hazard ratio.

early introduction of a palliative breathlessness support service for patients with refractory breathlessness (including COPD), but they did find improved breathlessness mastery, a quality of life domain of the Chronic Respiratory Disease Questionnaire. In contrast to patients with cancer in the palliative trajectory, for patients with advanced COPD in the palliative trajectory disease, oriented care remains necessary until the last weeks of life. It is possible that resilience to improve overall quality of life (especially symptoms and activity) is exhausted in this patient group, but further research is needed to test this hypothesis.

We did not find a difference in number and length of hospital readmissions. Previous research has demonstrated that the frequency of readmissions for an AECOPD is associated with functional limitation and poor health-related quality of life. ${ }^{30}$ The fact that there was no change in either of the conditions (SGRQ activity score and SGRQ total) between groups may explain our finding. Furthermore, post-discharge mortality is associated with COPD severity as well as specific comorbidities, especially cardiac disease. ${ }^{30}$ More patients in the intervention compared to the control group had severe dyspnea scores and CHF; however, we controlled for these confounders and found no difference in 1-year survival between groups.

During ACP conversations, patients are informed about their diagnosis, prognosis, their treatment options, and treatment consequences. Besides, patients can express their values and preferences for life-sustaining treatments with the goal of improving the quality of their end-of-life care. ${ }^{31}$ In our study, more patients in the intervention group made ACP choices and consequently had ACP conversations during the year. As follow-up of patients was too short, we were not able to confirm earlier findings that those ACP conversations actually increased the quality of end-of-life care. ${ }^{32,33}$ Further research is needed.

Our study has strengths and limitations. Although our pragmatic cluster controlled design completely ruled out contamination, this design was subject to selection bias at hospital level. However, by using outcomes of a pretrial assessment, we were able to control for confounders at hospital level. Besides, the small ICCs indicate that differences between hospitals not noteworthy contributed to the concerned study outcomes. Next, pulmonologists were aware of treatment allocation which may have caused bias. Our baseline data suggest that in the intervention group pulmonologists may have included patients with more advanced COPD since those patients would profit from extra support, whereas pulmonologists in the control group may have included patients with less advanced COPD in order to not additionally burden more vulnerable patients. We used these differences in patients' baseline characteristics to control for confounders at patient level. However, it is unclear whether all important differences were taken into account and the true effect may therefore be underestimated in this study. Furthermore, attrition is common in long duration trials testing palliative interventions and does not necessarily reflect poor design or conduct. ${ }^{34}$ The proportion of missing data typically increases with study duration; ${ }^{34}$ however, our proportion of missing data ( $28.5 \%$ at 3 months) was relatively low compared to the weighted estimate for missing data at primary end point of the palliative interventions $(23.1 \%$ at 28 days, median time), reported in a systematic review. ${ }^{34}$ Nevertheless, the width of 8 of the $95 \%$ CI of the primary outcome proved that, if present, our study had the power to detect the necessary minimal important difference (MID) of $4 .{ }^{35}$ Since the attrition rates in both groups were comparable, the threat to compromise the internal validity was minimal. ${ }^{34}$ We also have no reason to assume that the participating hospitals are not representative of other hospitals; consequently, our findings can be generalized to other general hospitals.

\section{Conclusion}

In this study, proactive palliative care did not improve the quality of life of patients with COPD at 3 months, as measured with the SGRQ. There are several possible reasons for this on identification, organization, patient, outcome measure, and disease course levels. Therefore, we recommend that future research on the effectiveness of proactive palliative care on quality of life in this patient group should take our findings into account. However, this study did demonstrate that proactive palliative care increased the number of patients who made ACP choices, and we therefore suggest that 
proactive palliative care in COPD should place emphasis on supporting patients through ACP conversations to improve their quality of care toward the end of life..$^{32,33}$

\section{Acknowledgments}

We thank the patients who participated in this study and their informal caregivers. We thank the clinical professionals and the administrative staff of the participating hospitals for their commitment and cooperation. We thank Jeroen Fokke for his support during the training in the hospitals. We thank Anne Ebenau and Klasminda Verhagen for their assistance with data entry and Aisha de Vries and Charlotte Gradussen for their assistance with the medical file study of participating patients.

This study was funded by the Netherlands Organization for Health Research and Development-ZonMw, The Hague. Project number: 80-82100-98-080. The funding source did not play any role in planning and implementing this study, interpreting its results, or in writing the paper.

\section{Author contributions}

All authors contributed toward data analysis, drafting and critically revising the paper, gave final approval of the version to be published, and agree to be accountable for all aspects of the work.

\section{Disclosure}

The authors report no conflicts of interest in this work.

\section{References}

1. Lozano R, Naghavi M, Foreman K, et al. Global and regional mortality from 235 causes of death for 20 age groups in 1990 and 2010: a systematic analysis for the Global Burden of Disease Study 2010. Lancet. 2012; 380(9859):2095-2128.

2. World Health Organization (WHO) [webpage on the Internet]. The 10 Leading Causes of Death in the World, 2000 and 2012. Available from: http://www.who.int/mediacentre/factsheets/fs310/en/. Accessed July 15, 2016.

3. Murray SA, Kendall M, Boyd K, Sheikh A. Illness trajectories and palliative care. BMJ. 2005;330(7498):1007-1011.

4. Suissa S, Dell'Aniello S, Ernst P. Long-term natural history of chronic obstructive pulmonary disease: severe exacerbations and mortality. Thorax. 2012;67(11):957-963.

5. Blinderman CD, Homel P, Billings JA, Tennstedt S, Portenoy RK. Symptom distress and quality of life in patients with advanced chronic obstructive pulmonary disease. J Pain Symptom Manage. 2009;38(1): 115-123.

6. Gore JM, Brophy CJ, Greenstone MA. How well do we care for patients with end stage chronic obstructive pulmonary disease (COPD)? A comparison of palliative care and quality of life in COPD and lung cancer. Thorax. 2000;55(12):1000-1006.

7. Bakitas M, Lyons KD, Hegel MT, et al. Effects of a palliative care intervention on clinical outcomes in patients with advanced cancer: the Project ENABLE II randomized controlled trial. JAMA. 2009;302(7): 741-749.
8. Temel JS, Greer JA, Muzikansky A, et al. Early palliative care for patients with metastatic non-small-cell lung cancer. $N$ Engl J Med. 2010;363(8): 733-742.

9. Zimmermann C, Swami N, Krzyzanowska M, et al. Early palliative care for patients with advanced cancer: a cluster-randomised controlled trial. Lancet. 2014;383(9930):1721-1730.

10. Brannstrom M, Boman K. Effects of person-centred and integrated chronic heart failure and palliative home care. PREFER: a randomized controlled study. Eur J Heart Fail. 2014;16(10):1142-1151.

11. Sidebottom AC, Jorgenson A, Richards H, Kirven J, Sillah A. Inpatient palliative care for patients with acute heart failure: outcomes from a randomized trial. J Palliat Med. 2015;18(2):134-142.

12. Higginson IJ, Bausewein C, Reilly CC, et al. An integrated palliative and respiratory care service for patients with advanced disease and refractory breathlessness: a randomised controlled trial. Lancet Respir Med. 2014;2(12):979-987.

13. Vermylen JH, Szmuilowicz E, Kalhan R. Palliative care in COPD: an unmet area for quality improvement. Int J Chron Obstruct Pulmon Dis. 2015;10:1543-1551.

14. Duenk RG, Heijdra Y, Verhagen SC, Dekhuijzen RP, Vissers KC, Engels Y. PROLONG: a cluster controlled trial to examine identification of patients with COPD with poor prognosis and implementation of proactive palliative care. BMC Pulm Med. 2014;14:54.

15. Kocks JW, Kerstjens HA, Snijders SL, et al. Health status in routine clinical practice: validity of the clinical COPD questionnaire at the individual patient level. Health Qual Life Outcomes. 2010;8:135.

16. Bestall JC, Paul EA, Garrod R, Garnham R, Jones PW, Wedzicha JA. Usefulness of the Medical Research Council (MRC) dyspnoea scale as a measure of disability in patients with chronic obstructive pulmonary disease. Thorax. 1999;54(7):581-586.

17. Lung Alliance Netherland (LAN). Richtlijn palliatieve zorg voor mensen met COPD; 2011. Available from: http://www.longalliantie.nl/files/9413/6752/1360/LAN_Richtlijn_Palliatieve_Zorg_ COPD-4spread.pdf. Accessed September 15, 2016.

18. Meguro M, Barley EA, Spencer S, Jones PW. Development and validation of an improved, COPD-specific version of the St. George Respiratory Questionnaire. Chest. 2007;132(2):456-463.

19. Jones PW, Quirk FH, Baveystock CM. The St George's Respiratory Questionnaire. Respir Med. 1991;85(suppl B):25-31. discussion $33-27$.

20. Cohen SR, Mount BM, Bruera E, Provost M, Rowe J, Tong K. Validity of the McGill Quality of Life Questionnaire in the palliative care setting: a multi-centre Canadian study demonstrating the importance of the existential domain. Palliat Med. 1997;11(1):3-20.

21. Spinhoven P, Ormel J, Sloekers PP, Kempen GI, Speckens AE, Van Hemert AM. A validation study of the Hospital Anxiety and Depression Scale (HADS) in different groups of Dutch subjects. Psychol Med. 1997;27(2):363-370.

22. Koff PB, Jones RH, Cashman JM, Voelkel NF, Vandivier RW. Proactive integrated care improves quality of life in patients with COPD. Eur Respir J. 2009;33(5):1031-1038.

23. Castor Electronic Data Capture (Castor EDC) [homepage on the Internet]. Available from: https://castoredc.com/. Accessed September $15,2016$.

24. Cohen J. A power primer. Psychol Bull. 1992;112(1):155-159.

25. Elkington H, White P, Addington-Hall J, Higgs R, Edmonds P. The healthcare needs of chronic obstructive pulmonary disease patients in the last year of life. Palliat Med. 2005;19(6):485-491.

26. Brumley RD. Future of end-of-life care: the managed care organization perspective. J Palliat Med. 2002;5(2):263-270.

27. Gershon AS, Dolmage TE, Stephenson A, Jackson B. Chronic obstructive pulmonary disease and socioeconomic status: a systematic review. COPD. 2012;9(3):216-226.

28. Horton R, Rocker G, Dale A, Young J, Hernandez P, Sinuff T. Implementing a palliative care trial in advanced COPD: a feasibility assessment (the COPD IMPACT study). J Palliat Med. 2013;16(1):67-73. 
29. Bucknall CE, Miller G, Lloyd SM, et al. Glasgow supported selfmanagement trial (GSuST) for patients with moderate to severe COPD randomised controlled trial. BMJ. 2012;344:e1060.

30. Steer J, Gibson GJ, Bourke SC. Predicting outcomes following hospitalization for acute exacerbations of COPD. QJM. 2010;103(11): 817-829.

31. Patel K, Janssen DJ, Curtis JR. Advance care planning in COPD. Respirology. 2012;17(1):72-78.

32. Detering KM, Hancock AD, Reade MC, Silvester W. The impact of advance care planning on end of life care in elderly patients: randomised controlled trial. BMJ. 2010;340:c1345.

33. Leung JM, Udris EM, Uman J, Au DH. The effect of end-of-life discussions on perceived quality of care and health status among patients with COPD. Chest. 2012;142(1):128-133.
34. Hussain JA, White IR, Langan D, et al. Missing data in randomized controlled trials testing palliative interventions pose a significant risk of bias and loss of power: a systematic review and meta-analyses. J Clin Epidemiol. 2016;74:57-65.

35. Jones PW. Interpreting thresholds for a clinically significant change in health status in asthma and COPD. Eur Respir J. 2002;19(3): $398-404$. 


\section{Supplementary material}

Table SI Change scores relative to baseline of McGill and HADS subscales and associated tests of effects between groups

\begin{tabular}{|c|c|c|c|c|c|c|c|}
\hline \multirow[t]{3}{*}{ Outcomes } & \multicolumn{4}{|c|}{ Descriptives } & \multirow{2}{*}{\multicolumn{3}{|c|}{$\begin{array}{l}\text { Analysis of difference between groups for } \\
\text { changes over time }^{a}\end{array}$}} \\
\hline & \multicolumn{2}{|c|}{ Intervention } & \multicolumn{2}{|c|}{ Control } & & & \\
\hline & $\mathbf{n}$ & $\begin{array}{l}\text { Mean (SD) } \\
\text { observed change } \\
\text { from baseline }\end{array}$ & $n$ & $\begin{array}{l}\text { Mean (SD) } \\
\text { observed change } \\
\text { from baseline }\end{array}$ & $\begin{array}{l}\text { Estimated } \\
\text { difference }(95 \% \mathrm{Cl})\end{array}$ & $\begin{array}{l}\text { Effect } \\
\text { size }^{\mathrm{b}}\end{array}$ & $p$-value \\
\hline \multicolumn{8}{|c|}{ McGillc physical well-being } \\
\hline 3 months & 61 & $0.15(2.95)$ & 85 & $0.72(2.87)$ & $0.15(-0.64$ to 0.95$)$ & -0.21 & 0.72 \\
\hline 6 months & 52 & $-0.35(2.60)$ & 73 & $-0.37(2.88)$ & $0.54(-0.16$ to 1.23$)$ & 0.01 & 0.16 \\
\hline 9 months & 47 & $0.43(2.94)$ & 64 & $-0.39(2.75)$ & $0.69(-0.13$ to $\mid .5 \mathrm{I})$ & 0.29 & 0.13 \\
\hline 12 months & 44 & $-0.16(2.82)$ & 59 & $0.08(2.97)$ & $-0.14(-1.22$ to 0.93$)$ & -0.08 & 0.82 \\
\hline \multicolumn{8}{|c|}{ McGill' physical symptoms } \\
\hline 3 months & 34 & $0.65(2.50)$ & 39 & $-0.03(2.32)$ & $0.66(-0.37$ to 1.68$)$ & 0.28 & 0.27 \\
\hline 6 months & 28 & $0.57(2.20)$ & 37 & $-0.03(2.42)$ & $\mathrm{I} .09$ (0.08 to $2.1 \mathrm{I})$ & 0.26 & 0.12 \\
\hline 9 months & 30 & $0.69(2.91)$ & 37 & $-0.4 I(2.52)$ & $0.97(-0.05$ to 1.99$)$ & 0.41 & 0.11 \\
\hline 12 months & 24 & $-0.19(2.15)$ & 32 & $-0.57(2.46)$ & $-0.13(-1.20$ to 0.82$)$ & 0.16 & 0.85 \\
\hline \multicolumn{8}{|c|}{ McGillc psychological } \\
\hline 3 months & 73 & $0.21(2.82)$ & 110 & $0.33(2.67)$ & $-0.01(-0.79$ to 0.76$)$ & -0.04 & 0.97 \\
\hline 6 months & 66 & $0.16(2.97)$ & 91 & $0.23(2.70)$ & 0.15 (-0.70 to 0.99$)$ & -0.02 & 0.77 \\
\hline 9 months & 61 & $0.38(2.43)$ & 87 & $0.09(2.64)$ & $0.35(-0.49$ to 1.20$)$ & 0.11 & 0.44 \\
\hline 12 months & 55 & $0.27(2.18)$ & 80 & $-0.17(2.95)$ & $0.49(-0.38$ to 1.37$)$ & 0.17 & 0.30 \\
\hline \multicolumn{8}{|c|}{ McGillc existential } \\
\hline 3 months & 75 & $0.37(1.75)$ & 111 & $0.24(2.29)$ & $0.36(-0.22$ to 0.95$)$ & 0.06 & 0.27 \\
\hline 6 months & 67 & $0.29(\mathrm{I} .6 \mathrm{I})$ & 92 & $0.38(2.17)$ & $-0.01(-0.52$ to 0.49$)$ & -0.05 & 0.99 \\
\hline 9 months & 63 & $0.08(2.03)$ & 89 & $0.14(2.18)$ & $-0.26(-0.96$ to 0.45$)$ & -0.03 & 0.58 \\
\hline 12 months & 55 & $0.08(2.18)$ & 82 & $-0.01(2.21)$ & $0.03(-0.70$ to 0.75$)$ & 0.04 & 0.94 \\
\hline \multicolumn{8}{|c|}{ McGill' support } \\
\hline 3 months & 73 & $-0.48(1.96)$ & 104 & $-0.63(2.46)$ & $0.37(-0.27$ to 1.01$)$ & 0.07 & 0.28 \\
\hline 6 months & 65 & $-0.93(2.32)$ & 89 & $-0.36(2.17)$ & $-0.34(-1.01$ to 0.32$)$ & -0.26 & 0.39 \\
\hline 9 months & 59 & $-0.63(1.97)$ & 86 & $-0.98(2.29)$ & $0.21(-0.50$ to 0.93$)$ & 0.16 & 0.58 \\
\hline 12 months & 53 & $-0.66(2.25)$ & 78 & $-0.99(2.10)$ & $0.52(-0.25$ to 1.28$)$ & 0.15 & 0.21 \\
\hline \multicolumn{8}{|l|}{ HADS $^{d}$ anxiety } \\
\hline 3 months & 76 & $-0.29(4.03)$ & 111 & $-0.27(3.77)$ & $-0.12(-1.21$ to 0.97$)$ & -0.01 & 0.83 \\
\hline 6 months & 66 & $-0.46(4.35)$ & 90 & $-0.52(3.75)$ & $0.02(-1.26$ to 1.29$)$ & 0.01 & 0.98 \\
\hline 9 months & 62 & $-1.23(4.29)$ & 87 & $-0.26(3.79)$ & $-0.65(-2.1 I$ to $0.8 I)$ & -0.24 & 0.41 \\
\hline 12 months & 55 & $-0.38(4.34)$ & 81 & $0.17(3.82)$ & $-0.12(-1.55$ to 1.32$)$ & -0.14 & 0.88 \\
\hline \multicolumn{8}{|c|}{ HADS $^{d}$ depression } \\
\hline 3 months & 76 & $0.5 I(3.65)$ & 111 & $0.53(3.59)$ & $-0.25(-1.33$ to 0.83$)$ & -0.01 & 0.66 \\
\hline 6 months & 66 & $0.91(3.83)$ & 89 & $0.90(3.67)$ & $-0.30(-1.43$ to 0.82$)$ & 0.00 & $0.6 \mathrm{I}$ \\
\hline 9 months & 62 & $1.20(3.91)$ & 87 & $0.59(3.55)$ & $0.15(-1.1 I$ to $\mid .4 I)$ & 0.16 & 0.82 \\
\hline 12 months & 55 & $1.21(3.88)$ & 80 & 1.20 (3.79) & $-0.78(-2.30$ to 0.74$)$ & 0.00 & 0.42 \\
\hline
\end{tabular}

Notes: Associated tests of effects between groups were estimated by linear mixed models, adjusted for baseline covariates. Analyses were performed following the principle of intention to treat. Missing data were handled using available case analysis. Descriptive data are mean (SD) unless otherwise stated.The ICCs of the questionnaire outcome measures were all very small near 0 or 0 and therefore not displayed. ${ }^{a}$ Associated tests of effect between groups were estimated by linear mixed models, adjusted for baseline covariates. ${ }^{b}$ Effect sizes are Cohen's d, 0.20 is small, 0.50 is moderate, and 0.80 is large. ${ }^{c}$ Change score interpretation: high score better. ${ }^{~} \mathrm{Change}$ score interpretation: low score better.

Abbreviations: Cl, confidence interval; HADS, Hospital Anxiety and Depression Scale; ICC, intraclass correlation coefficient; McGill, McGill Quality of Life Questionnaire; SD, standard deviation.

\section{Publish your work in this journal}

The International Journal of COPD is an international, peer-reviewed journal of therapeutics and pharmacology focusing on concise rapid reporting of clinical studies and reviews in COPD. Special focus is given to the pathophysiological processes underlying the disease, intervention programs, patient focused education, and self management protocols

\section{Dovepress}

This journal is indexed on PubMed Central, MedLine and CAS. The manuscript management system is completely online and includes a very quick and fair peer-review system, which is all easy to use. Visit $\mathrm{http} / / / \mathrm{www}$.dovepress.com/testimonials.php to read real quotes from published authors. 